\title{
La reconfiguración del proceso de trabajo docente bajo el confinamiento provocado por la pandemia ${ }^{1}$
}

\author{
Reconfiguring the Teaching Process under \\ COVID-19 Pandemic's Confinement
}

Fecha de recepción: 26/05/2021

Fecha de aceptación: 14/09/2021

Fecha de publicación: 24/01/2022

https://doi.org/10.48102/if.2022.v2.n2.188

\author{
Rodrigo Eduardo Ocampo Merlo* \\ red_ocampo@hotmail.com \\ ORCID: https://orcid.org/0000-0002-4341-5316 \\ Doctor en Estudios Sociales \\ Universidad Nacional Autónoma de México \\ México
}

\author{
Angélica Cuéllar Vázquez** \\ acuellarunam@gmail.com \\ ORCID: https://orcid.org/0000-0002-7952-7141 \\ Doctora en Sociología \\ Universidad Nacional Autónoma de México \\ México
}

\begin{abstract}
1 Investigación realizada gracias al apoyo del Programa de Becas Posdoctorales en la UNAM que emite la Dirección General de Asuntos del Personal Académico. La entidad académica que acogió este proyecto fue la Facultad de Ciencias Políticas y Sociales de la UNAM.

* Doctor en Estudios Sociales por la Universidad Autónoma Metropolitana (UAM-I). Su línea de investigación son los estudios laborales. Sus publicaciones más recientes son el capítulo "Las relaciones laborales a cien días de gobierno obradorista" (UAM, 2020) y el artículo "Un análisis de la reestructuración del campo educativo en México a la luz de las modificaciones a su marco regulatorio en el nivel Básico" (2021), publicado en la revista Sociológica en coautoría con la doctora Angélica Cuéllar Vázquez.

** Doctora en Sociología por la Facultad de Ciencias Políticas y Sociales de la UNAM. Su línea de investigación es la sociología jurídica. Sus publicaciones más recientes son La justicia alternativa. Una mirada sociológica a la justicia restaurativa (Tirant lo Blanch, 2018) y Representaciones sociales sobre el adolescente en conflicto con la ley: de las normas a las prácticas (Tirant lo Blanch, 2021).
\end{abstract}




\section{Resumen}

El objetivo de esta investigación es exponer la forma en la que se reconfiguró el trabajo docente ante el confinamiento provocado por la pandemia derivada del virus SARS-CoV-2. Un cambio que obligó el traslado de la práctica docente al ámbito privado a través del trabajo en línea y a foros televisivos por medio del programa Aprende en Casa. Esta modificación exigió al magisterio adecuar los componentes emocionales, estéticos, éticos y de cuidado de su trabajo a las condiciones tecnológicas, interactivas y espaciales de los ámbitos mencionados. El desarrollo de la investigación demandó hacer una reconstrucción de los debates en torno al proceso de trabajo en servicios; cuestión que permitió analizar las particularidades físicas, relacionales y subjetivas que se incorporaron al trabajo del cuerpo docente de una escuela primaria de la Ciudad de México. Las propuestas teórico-metodológicas del "trabajo no clásico" y el configuracionismo latinoamericano sirven de guía a este artículo.

\section{Palabras clave}

Trabajo no clásico, configuracionismo, trabajo docente, pandemia, proceso de trabajo.

\section{Abstract}

The purpose of this research is to illustrate on the way in which teaching has been reshaped during the confinement caused by the SARS-CoV-2 pandemic. The latter forced the relocation of teaching practices to the private sphere, through online platforms and TV forums such as the Aprende en casa project. Such changes required teachers to adapt the emotional, aesthetic, ethical, and care components of their trade to the technological, interactive, and aspatial conditions of the aforementioned environments. The development of the research required reconstructing debates on labour processes in the service sector, in order to analyze the physical, relational, and subjective particularities that became part of the duties of teaching staff in a primary school in Mexico City.

\section{Keywords}

Non-classical work, Latin American configurationism, teaching work, pandemic, labour process. 


\section{Introducción}

La alternancia en el poder de 2019 en México de la mano de Andrés Manuel López Obrador puso en el horizonte la discusión y posterior aprobación de una reforma educativa que tuvo como objetivo eliminar el contenido punitivo vinculado a la evaluación que sostenía la normativa anterior. Un cambio que, de acuerdo con la administración obradorista, regresaría al magisterio parte de su dignidad vulnerada por gobiernos anteriores; sin embargo, la puesta en marcha de la ley y su consecuente institucionalización se vieron interrumpidas abruptamente a causa de la pandemia mundial derivada del virus SARS-CoV-2.

La crisis sanitaria no sólo frenó la operatividad del nuevo ordenamiento al obligar el cierre de escuelas como estrategia de salud pública, sino que exigió la creación de un plan que en condiciones de confinamiento permitiera dar continuidad al calendario escolar y suplir las clases presenciales. El proyecto Aprende en Casa fue una de las opciones adoptadas por las autoridades; estuvo enfocado en la producción de programas televisivos que abordaron por materia y por grado escolar el contenido oficial de los planes de estudio del nivel básico. El peso de la conducción de dichos programas recayó en docentes pertenecientes al sector público, quienes se integraron a la actividad mediante la convocatoria emitida por la Secretaría de Educación Pública (SEP). Como complemento a la opción televisiva, la SEP gestionó con personal docente la posibilidad de impartir clases en línea, cuestión que tuvo resultados diversos, ya que sólo algunos centros educativos accedieron a emprender dicha tarea y la forma en la que lo hicieron no fue uniforme.

En este estudio, se retoma el caso de un docente que se vinculó al proyecto televisivo, así como el caso de la escuela primaria en la que labora, la cual adoptó la estrategia educativa en línea; esto permite reconstruir la reconfiguración del proceso de trabajo docente en ambos ámbitos. El centro escolar seleccionado forma parte del programa denominado "Escuelas de Tiempo Completo", creado en 2007 con el objetivo de ampliar el horario de clases como una estrategia de mejora educativa bajo la premisa de que la extensión de la jornada escolar repercute en un aprovechamiento más adecuado de los contenidos educativos. La escuela primaria tiene un solo turno con horario de las 8:00 a.m. a las 4:00 p.m.; además, como parte de sus actividades, incluye el servicio de comedor para el alumnado. Los profesores de educación física e inglés están contratados por hora; el 
resto de la planta, por jornada laboral; una característica que es importante considerar ya que, como se verá, el confinamiento pandémico diluyó la estructuración del tiempo de trabajo del conjunto de docentes, cuestión que derivó en una intensificación de su carga laboral.

La estrategia de recolección de datos seguida en este estudio fue la etnográfica digital, la cual reconoce que los medios y tecnologías digitales forman parte de la cotidianidad y que la formación experiencial de las personas ya no puede entenderse sin la interacción con estas herramientas (Pink et al., 2019). Este método implicó la creación de vínculos con informantes mediados por la tecnología, el análisis de videos - para el caso del docente vinculado a la televisión- que fueron abordados como textos, así como la observación y descripción de interacciones virtuales producto de la impartición de clases en línea. El acercamiento etnográfico problematizó la interacción docente con las tecnologías, con los entornos espaciales y con los múltiples sujetos que intervienen en el desarrollo del proceso de trabajo. La oportunidad de presenciar clases de educación física y de profesores de aula bajo la modalidad citada se complementó con nuestra incorporación a juntas en línea del centro escolar y con la elaboración de entrevistas semiestructuradas a docentes y autoridades del centro escolar. Las actividades se realizaron durante los meses de agosto, septiembre, octubre y noviembre de 2020; una de las entrevistas pudo concertarse hasta enero de 2021.

Como señalan Pink et al. (2019), el recurso etnográfico suele guiarse por esquemas teóricos y metodológicos diversos, lo que propicia que los proyectos evolucionen de formas no homogéneas; para nuestro caso, el análisis del proceso de trabajo que pone énfasis en la dimensión del control toma como referencia el enfoque del "trabajo no clásico" elaborado por Enrique de la Garza (2011a, 2017), el cual permite entender a la actividad docente como un trabajo interactivo que pone en juego habilidades cognitivas, emocionales, estéticas y de cuidado; dimensiones cuya ejecución es negociada o impuesta frente a autoridades, estudiantes y sus entornos familiares. Además de las presiones interactivas, la propuesta exige reconocer que existen condicionamientos estructurales de diverso orden que intervienen en la concreción de la práctica, como pueden ser las situaciones de trabajo que impone el confinamiento, el uso de nuevas tecnologías y las limitaciones que imprimen a la docencia estas herramientas. Aunque pueden presentarse diversos factores que coartan las potencialidades de la 
acción, el planteamiento del autor puntualiza que no logran determinarla; cuestión que dota de agencia a los sujetos, quienes además construyen significados diferenciados para la situación concreta, evaluándose intersubjetivamente lo que debe entenderse por cuidado o una emoción pertinente para ejecutar el trabajo. La consideración del juego que se establece entre estructuras, subjetividades y acciones exigió vincular la propuesta "no clásica" con el enfoque metodológico del configuracionismo latinoamericano que recupera el concepto del sujeto-objeto para la reconstrucción de lo real concreto (Garza de la, 2012).

El artículo presenta, en un primer apartado, la manera en la que se ha problematizado el tema del control sobre el proceso de trabajo en actividades interactivas; se expone la pertinencia del "trabajo no clásico" para el abordaje de nuestro caso de análisis. En un segundo apartado, se reconstruye la reconfiguración de la práctica docente que se ligó a la televisión y de la involucrada en las clases en línea. Finalmente, como parte de las conclusiones, se enuncia la forma en la que los componentes físicos, relacionales y subjetivos de la práctica docente se modificaron para enfrentar el confinamiento; una estrategia de adaptación al proceso de trabajo que se estructuró bajo condiciones flexibles de trabajo y requirió la puesta en juego de esfuerzos individuales.

\section{El trabajo no clásico como propuesta analítica}

Los estudios del trabajo nacieron vinculados al análisis de la actividad industrial; el interés estaba puesto en la comprensión del trabajo al interior de las fábricas, lo que desestimaba la construcción de categorías para entender el ámbito de los servicios. Un sesgo que no era el resultado de un simple descuido, sino la consecuencia de que el discurso de la modernidad estuviera estrechamente vinculado al desarrollo industrial; el éxito o fracaso del proyecto pasaba por la cadena de montaje.

Una de las líneas de investigación que siguió la sociología del trabajo fue el análisis de los procesos de trabajo: se problematizaban las formas de control que operaban bajo la organización taylorista-fordista de la producción. Éste fue un desarrollo teórico que buscó desenredar las particularidades de una actividad productora de objetos materiales en la que las esferas de la producción, circulación y consumo aparecen claramente diferenciadas, y en la que la participación del cliente cobra 
relevancia hasta el último momento del circuito que sigue la reproducción y acumulación del capital.

Siguiendo esta línea, se desarrollaron formulaciones teóricas como la de Harry Braverman (1974), que tendría gran acogida en el mundo anglosajón y latinoamericano. Desde un enfoque marxista, el autor argumentaba que la incorporación de tecnología al proceso productivo evidenciaba la intención gerencial por controlar la fuerza de trabajo simplificando sus tareas, es decir, las herramientas tecnológicas eran el instrumento por excelencia para descalificar las habilidades obreras y volver al trabajador un elemento de fácil reemplazo. Lo que se había hecho pasar por una administración científica del trabajo era, en realidad, una forma de organizar la producción bajo condiciones capitalistas de explotación en las que el obrero tenía mínima capacidad de injerencia y control sobre los tiempos y movimientos de su actividad. Aunque la propuesta de Braverman subestimó la capacidad reflexiva de los sujetos y, por consiguiente, la posibilidad de articular resistencias aun bajo un control de la producción cada vez más sofisticado, tuvo el acierto de cuestionar el optimismo liberador que acompañó el desarrollo tecnológico durante la década de los cincuenta y sesenta, el cual auguraba la formación de un capitalismo benevolente (Garza de la, 2011b).

Sin embargo, el planteamiento del autor - que daría pie al surgimiento de otras teorizaciones que buscaban establecer mediaciones al tema de la dominación incorporando nociones como las de la construcción de consenso en el lugar de trabajo (Burawoy, 1979) - había quedado atado al mundo fabril. Una limitación que obligaba a preguntarse: ¿̇son suficientes las categorías de la sociología industrial para comprender el empleo informal, el autoempleo y el sector servicios?, ¿qué pasa con los trabajos en los que el proceso de producción, circulación y consumo se comprime en el mismo acto?, ¿cómo explicar los trabajos cuyo componente central es la producción de interacciones que requieren de la presencia del cliente-usuario para realizarse?, ¿cómo dar cuenta de los elementos que configuran el trabajo que produce símbolos en escenarios musicales, teatrales o en programas televisivos?

Autores como de la Garza (2011a) consideraron que la respuesta a estas preguntas no era sencilla y que, si bien era cierto que la teorización clásica del trabajo se había enfocado en el ámbito industrial, sus aportaciones no podían simplemente desecharse; por el contrario, podían ser recuperadas al incorporar nuevas determinaciones a conceptos como los de control, regulación del trabajo y mercado de trabajo. La cuestión era cómo 
pensar el control sobre el proceso de trabajo en actividades productoras de símbolos, en empleos cuyo rasgo principal es la producción de emociones, de cuidado, o, bien, en ocupaciones en las que la performatividad en tanto producción estética resulta central.

En un intento por atender los vacíos teóricos enunciados, de la Garza (2011a, 2017) desarrolló la propuesta del "trabajo no clásico", que buscaba distanciarse de las formulaciones sociodemográficas que caracterizaban al trabajo en servicios, a los informales y al autoempleo a partir de su condición asalariada, nivel de ingreso, edad, género, acceso a seguridad social, entre otras variables. En contra parte, de la Garza reconoce que la comprensión de estos trabajos debe pensarse a partir de su particularidad interactiva en la que el cliente-usuario incide de manera directa en la forma en la que se concreta el servicio; por ejemplo, cuando se demanda atención amable y rápida en un restaurante. El contenido interactivo del trabajo aparece bajo este enfoque como un vínculo mediado por el poder, en el que las fronteras de control sobre el proceso de trabajo pueden negociarse frente a las gerencias, clientes-usuarios y otros sujetos que indirectamente inciden en la regulación del trabajo. Expuesto lo anterior, el contenido del concepto control requiere ampliarse, sin quedar ligado solamente a la tecnología o a la organización del trabajo, es decir, la coerción se ejerce también sobre la producción de emociones, de estética y de cuidado. Asimismo, para de la Garza, el factor de control no puede aparecer disociado de la resistencia; la relación dialéctica de estas dimensiones son parte de un mismo proceso; de lo contrario, la agencia de los sujetos se diluye y queda subsumida sin contradicciones a los intereses del capital.

Es preciso decir que el "trabajo no clásico" discute con teorías que nacieron en la década de los ochenta y con planteamientos posteriores que refinaron la discusión sobre la estandarización del trabajo en los servicios. Para estos enfoques, el control gerencial sobre el proceso de trabajo se traslada al dominio de las emociones, del cuerpo, a la construcción estética de la performatividad de la actividad, e incide en la forma en la que se ejerce el cuidado. Un estudio pionero que buscó explicar el tema del control en los trabajos interactivos lo realizó Arlie Hochschild (2003) en 1983, quien propuso el concepto emotional work para entender y analizar el trabajo de sobrecargos. Para esta autora, en los servicios -a diferencia del trabajo industrial, cuyos tiempos y movimientos están determinados por las máquinas-, el dominio se inserta en el self, esto es, se exige que 
de forma consciente el trabajador adecúe sus movimientos corporales y faciales a las exigencias del modelo de negocio de la compañía. Un control de las emociones que, según Hochschild, puede seguir dos vías: por un lado, el despliegue de un trato amable y la expresión de una sonrisa pueden manifestar un actuar superficial que no corresponde con el self de quien los produce; por otro lado, se puede desarrollar un actuar profundo que encuentra correspondencia entre el sentimiento y la acción. El problema del carácter dual del trabajo emocional deviene cuando la reglamentación de las emociones (feeling rules) se encuentra en contradicción con el sentir del trabajador, es decir, cuando se ve obligado a realizar un actuar superficial; condición que genera disonancias emocionales que implican malestar y desgaste. Para Hochschild, el control de la performatividad del self implica una alienación de las emociones, un despojo gerencial de la capacidad creativa que exige la estandarización y rutinización del trabajo.

Aunque los postulados de este planteamiento resultan sugerentes, se puede señalar que la alienación de la subjetividad no se da de forma tan mecánica y, aunque los procesos de control de las interacciones pueden volverse férreos, el sabotaje, la resistencia y la inconformidad de los empleados pueden incidir en la concreción de la producción del servicio. Al igual que Braverman, Hochschild subestimó la capacidad reflexiva de los sujetos al asumir que existe un control total de la subjetividad, lo que niega la posibilidad de que en el encuentro interactivo se desprendan resistencias e incluso improvisaciones al proceso de trabajo. Un planteamiento que, además, omitió considerar que las interacciones no se dan en el vacío, es decir, la reconstrucción del trabajo emocional debe contemplar el tipo de regulación que media las relaciones de producción, cómo interviene la tecnología, cuál es el perfil de los trabajadores, qué tipo de cultura laboral prevalece (Garza de la, 2017).

El trabajo emocional sirvió de base para el desarrollo de propuestas que pusieron énfasis en el vínculo cuerpo-trabajo, discusiones que destacaron la manera en la que las inequidades sociales y de acceso al empleo se expresan también por medio de las competencias corpóreas. Para estas teorías, el cuerpo se vuelve un recurso más de trabajo, una herramienta con dimensiones físicas y estéticas, y cuya modificación y adaptación se pone en juego para insertarse en ocupaciones particulares o en culturas corporativas específicas (Wolkowitz, 2006). Bajo esta óptica, el cuerpo aparece como un recurso maleable que requiere adecuarse constantemente a las varia- 
ciones que se dan en el plano de las relaciones laborales y del proceso de trabajo. La estructura aparece como determinante de la corporalidad, por lo tanto, a los sujetos sólo les quedaría la tarea de amoldar su instrumento a los designios gerenciales. De acuerdo con Wolkowitz (2006), el análisis de los diferentes elementos que conforman al cuerpo permitiría superar el reduccionismo subjetivo en el que había caído Hochschild; sin embargo, este planteamiento cae en el otro extremo al sobreestimar el peso de las estructuras y reducir la valía de la fuerza de trabajo a su capacidad de atender exigencias físicas y estéticas del capital.

Siguiendo la crítica al emotional work, surgieron problematizaciones que entendieron el trabajo interactivo como productor de estética. Para Anne Witz et al. (2003), los trabajadores, además de ser para las gerencias un software controlable, son un hardware en la medida en que incorporan al cuerpo la estética organizacional; en este sentido, la expresión emotiva de Hochschild resultaba insuficiente para entender la producción corporativa del cuerpo. El trabajo estético implica movilización, desarrollo y mercantilización de las disposiciones corpóreas, esto es, la obtención de un empleo exige también movilización de capacidades y habilidades con implicaciones físicas y subjetivas (Witz et al., 2003). Las corporaciones demandan al trabajador la producción de un particular estilo de caminar, hablar o vestir, el cual debe resultar acorde con la estética de la compañía y, al mismo tiempo, servir de referencia al potencial consumidor.

Como señalan Witz et al. (2003) siguiendo a Pierre Bourdieu y Erving Goffman, la encarnación de una estética corporativa exige una transformación profunda de las prácticas y las emociones, las cuales se vuelven un habitus que no sólo expresa posesión de habilidades sino una forma de ser; asimismo, el trabajo estético no puede ser reducido al de control de las emociones, ya que su componente objetivo se vuelve central para la escenografía del servicio que se produce. Aunque la propuesta del trabajo estético incorpora elementos que pueden resultar novedosos, el peso de las estructuras de control gerencial luce desdibujado; el poder y la dominación se reducen a una dimensión estética que se interioriza irreflexivamente como habitus; el sujeto participa inconscientemente en su propia explotación. Bajo esta lógica, la regulación de las relaciones laborales resultaría ociosa e irrelevante, ya que el trabajador ha aceptado sin resistencia la estética y el habitus organizacional. 
Otro planteamiento que se encuentra en el horizonte de la discusión del "trabajo no clásico" es el que entiende el trabajo como productor de cuidados. Una propuesta que tiene su origen en el tema sobre la desigualdad vinculada al género y las luchas políticas que buscan visibilizar principalmente el trabajo doméstico, actividad a la que se le han asignado connotaciones morales que desdibujan su condición de subalternidad (Gilligan, 1985). La problematización del cuidado puso de relieve, también al inicio de la década de los ochenta, la centralidad que en la sociología del trabajo ocupaban las actividades asalariadas vinculadas al género masculino. Uno de los enfoques que buscó dar un giro a la teorización dominante fue el psicodinámico, cuyo planteamiento analiza el trabajo de cuidado como una relación de dependencia que se estructura bajo condiciones de dominación y se monta sobre "una ética cuyo modelo es el de la familia vista como el reino de las relaciones basadas en el afecto, la preocupación por el otro, de la reciprocidad" (Arango, 2011, p. 101). Para esta propuesta, resulta primordial problematizar el ejercicio del poder detrás de lo que aparece como un vínculo afectivo natural generado en el ámbito de lo privado, particularidad ética que se ha asignado a los trabajos en educación básica, salud y asistencia social (Arango, 2011).

La literatura en torno al trabajo de cuidado es abundante y presenta variaciones; no obstante, Sandra Franco (2015) considera que pueden identificarse claramente tres corrientes: 1) el cuidado en clave de trabajo, que busca visibilizar la explotación de las mujeres en la esfera de la reproducción; 2) el cuidado en clave de emociones, que hace referencia a las actividades en las que la producción de sentimientos es central, y 3) el cuidado en clave de prácticas sociales, donde se cuestionan las limitaciones de la institucionalidad estatal para atender el desarrollo y protección del sector de la población que ejerce este trabajo. De estos enfoques, es importante problematizar la forma en la que las connotaciones éticas y morales embebidas en el trabajo de cuidado entran en tensión durante el despliegue del proceso de trabajo, el cual se realiza frente a un cliente-usuario que no sólo es receptor de cuidado, sino que es agente activo que interviene presionando en la manera en la cual se concreta la actividad (Garza de la, 2011a, 2017).

Como ha quedado de manifiesto, una de las principales limitaciones que presentan las teorías expuestas es que, al dar prioridad a lo emocional, lo estético, lo corpóreo y el cuidado, desestiman que en lo real concreto 
pueden encontrarse articuladas estas dimensiones en forma de red y, aunque una particularidad puede ser dominante, ello no implica la negación de la otra. Otra cuestión que se pasa por alto es que las dimensiones señaladas no sólo forman parte de la actividad trabajo: pueden estar también contenidas en el producto que no se reduce a ser un objeto material (Garza de la, 2017); por ejemplo, la valoración de una escuela puede depender no sólo de sus virtudes académicas, sino de los componentes estéticos, emocionales y de cuidado que ofrece. Asimismo, ninguna de las propuestas destaca el trabajo del cliente-usuario ni la composición de clase de este sujeto, cuestión que puede afectar en mayor o menor medida el proceso de trabajo. Tampoco se toma en cuenta que la construcción de significados y códigos (estéticos, emocionales, éticos) se impone o negocia entre trabajadores y consumidores, quienes se encuentran inmersos en estructuras que presionan sin determinar sus acciones.

La discusión con las teorías expuestas, la recuperación y ampliación de conceptos emanados de la sociología industrial y la formulación de preguntas en torno a qué y cómo se produce en ámbitos como el de servicios le permitieron a de la Garza (2017) identificar tres formas de "trabajo no clásico" cuyas características pueden presentarse separadas, combinadas o, incluso, pueden reconocerse en actividades "clásicas"; estas formas son: 1) el trabajo interactivo, 2) la producción de símbolos sin intervención del cliente-usuario y 3) los trabajos que requieren del trabajo del cliente-usuario para realizarse.

El primer tipo de trabajo al que se hace referencia es aquél en el que la interacción es parte central de lo que se produce; la impartición de clases presenciales y en línea puede entenderse dentro de esta categoría, es decir, la actividad docente bajo esta modalidad requiere la presencia del otro para concretarse; un otro que además presiona la forma en la que se ejecuta el trabajo en el mismo instante en el que se produce. En estos trabajos, el concepto de regulación laboral precisa ser ampliado y no quedar limitado a la díada clásica que compone la relación capital-trabajo. Para el caso de la docencia en línea, el control sobre el proceso de trabajo está intervenido por la presencia de terceros - como puede ser el entorno relacional- que configuran el espacio donde se toma la clase; por lo tanto, el profesorado debe desarrollar habilidades no sólo pedagógicas, sino emocionales, estétia cas y de cuidado que atiendan las exigencias de los diferentes sujetos frente a los que también se negocia la cotidianidad del orden (Edwards, 1990). 
La segunda forma de trabajo es la que produce símbolos sin intervención del cliente-usuario; en ella, podemos ubicar la labor docente vinculada a la televisión. Un acto productivo del que interesa analizar no tanto el contenido del conocimiento educativo que genera, sino la forma en la que el trabajo docente objetiva dicho material pedagógico y lo despliega a través de la creación de signos auditivos, semióticos y visuales dentro de un escenario que requiere instrumentos técnicos para la transmisión de lo que se produce (Garza de la, 2017). Cabe destacar que, a diferencia del trabajo en línea, en la actividad vinculada a la televisión las esferas de la producción, circulación y consumo se encuentran claramente segmentadas; por lo tanto, el control sobre el proceso de trabajo requiere incorporar mediaciones distintas a las que intervienen en la interacción directa e inmediata con el cliente-usuario.

El tercer tipo engloba los trabajos que requieren la intervención del cliente-usuario para que puedan realizarse; una actividad que ejemplifica esto claramente es el funcionamiento de los restaurantes de comida rápida, en donde la figura del mesero es sustituida por el cliente que tiene que realizar por su cuenta el pedido, pago y recolección de alimentos; además de que se mantiene como parte de una regla de operatividad que el comensal limpie la mesa depositando los sobrantes y basura en los cestos destinados para ello. Como se verá en el siguiente apartado, la intervención de los familiares en el envío de tareas por correo electrónico se volvió fundamental para dar funcionalidad a las actividades escolares bajo el confinamiento; la negativa a desempeñar dichas acciones simplemente hubiera vuelto inviable completar el círculo de la práctica docente a distancia.

Una vez expuesto que el trabajo docente en su modalidad televisiva y en línea puede ser entendido a partir de las formas de trabajo no clásicas, es necesario enfatizar que las condiciones de producción serán analizadas dentro de un contexto de encierro derivado de la pandemia, el cual exigió la formación súbita y repentina de nuevas calificaciones laborales cuyo desarrollo dependió de esfuerzos particulares que fueron paulatinamente complementados por la institucionalidad educativa. Jorge Carrillo y Consuelo Iranzo (2003) consideran que la discusión en torno a la definición del concepto de calificación laboral puede entenderse como una construcción social cuya configuración depende de las particularidades del sector; sin embargo, en términos generales, implica la incorporación de saberes tácitos y técnicos para la resolución de problemas que aparecen de pronto 
en la producción. Un conjunto de saberes que en momentos coyunturales requieren ser modificados.

Lo anterior pasó con el trabajo docente, sólo que el proceso de transa formación para el sector no fue progresivo ni requirió la puesta en marcha de una política educativa planificada que nivelara las competencias del magisterio para enfrentar los cambios. Los ajustes físicos, relacionales y subjetivos de los docentes simplemente debieron improvisarse con adecuaciones no sólo a sus competencias cognitivas, sino al desarrollo de habilidades emocionales, estéticas y de cuidado que están intrínsecamente vinculadas a su práctica. Cabe precisar que la reconfiguración del trabajo docente no se dio en el vacío: implicó una renegociación de las fronteras del control del proceso de trabajo frente a las autoridades, los alumnos y los entornos familiares. En otras palabras, el problema no se limitó a definir qué contenidos educativos debían darse y cómo debían ser impartidos, sino que requirió replantear la performatividad de la práctica misma.

Dicho lo anterior, en el siguiente apartado se reconstruye la reconfiguración del trabajo docente bajo el confinamiento en su modalidad televisiva y en línea. La exposición de los casos busca evidenciar las condicionantes estructurales, relacionales y subjetivas que intervinieron en la concreción de estas prácticas.

\section{La reconfiguración de la práctica docente}

La suspensión de actividades esenciales a causa de la pandemia implicó la adopción de estrategias para concluir el ciclo escolar 2019-2020; dar continuidad al calendario resultó una prioridad en un contexto de crisis mundial sanitaria. Para las autoridades, era menester que los docentes siguieran con su labor aun en condiciones de confinamiento; por lo tanto, debían encontrarse los caminos y las modalidades para no perder el vínculo con el estudiantado. En el plantel analizado en esta investigación, la comunicación entre autoridades y docentes, y de estos últimos con los familiares que transmitirían finalmente a los alumnos los lineamientos a seguir para dar continuidad al proceso de enseñanza, se generó mediante recursos tecnológicos; los canales empleados fueron el envío de mensajes de texto y de correos electrónicos.

El uso de equipos electrónicos para mantener el vínculo entre el centro escolar y los alumnos representó al menos dos problemas: en primer lugar, los sujetos intervinientes en la producción del servicio educativo tu- 
vieron que dotarse de herramientas tecnológicas que, entre otras cosas, requerían conexión a internet, cuyo pago tuvo que ser cubierto de forma individual; en segunda instancia, se vieron obligados a desarrollar o afinar habilidades técnicas para el manejo de estos dispositivos. Si bien es cierto que el uso de dispositivos electrónicos resultó una nimiedad para un sector del cuerpo docente, la distribución de saberes no era uniforme; al respecto, una profesora comentó en una junta en línea: "hay algunos de aquí que sí le saben bien a la computadora, pero a mí mi hija me tuvo que estar enseñando a cómo enviar los correos [...] todavía me cuesta" (Nota de campo, 21 de septiembre de 2020).

Aunque inicialmente la demanda de habilidades tecnológicas se centró en el envío de mensajes de texto y correos electrónicos, a unas semanas de iniciado el confinamiento, ${ }^{2}$ comenzaron a agendarse reuniones docentes a través de la plataforma Zoom; el uso de esta herramienta exigió una nueva movilización de saberes que tendría que ser solventada también de forma individual. Cabe señalar que la adopción de esta modalidad comunicativa no fue tersa: una parte de los profesores se negó a emplearla argumentando no contar con equipos, no saber cómo usar el software, no contar con la conectividad adecuada, además de mencionar que las juntas en línea invadían su privacidad (Autoridad, comunicación personal, videollamada, 13 de octubre de 2020). No fue sino hasta que concluyó el ciclo escolar que la SEP emitió cursos en línea para el uso de Google Meet como instrumento oficial para la comunicación virtual; sin embargo, las resistencias y cuestionamientos al uso de estas herramientas se mantuvieron.

Como puede verse, la reconfiguración del trabajo no tuvo que esperar el inicio de clases en línea: los docentes tuvieron que aprender el manejo de los softwares en cuestión para recibir instrucciones laborales y, aunque algunos se resistieron inicialmente a usarlos, finalmente accedieron a emplearlos porque la negociación de la estrategia educativa a seguir se disputaba en las juntas virtuales (Nota de campo, 28 de agosto de 2020). La creación de reuniones en línea sirvió como primera experiencia en el uso de una herramienta que sería central para el desempeño docente, instrumento tecnológico que sustituyó el espacio físico del aula y suprimió parte de las competencias que el docente despliega en este ámbito como parte de su proceso de trabajo. La forma de caminar en el salón, los cambios en la disposición del cuerpo para atender situaciones concretas e interactuar con

2 En México, el 20 de marzo de 2020 se suspendieron las clases por la pandemia. 
los alumnos simplemente se modificaron, la retroalimentación que aporta la interacción cara a cara tuvo que buscarse en la pantalla del computador, en perfiles de alumnos cuya cámara podía estar apagada y donde el intercambio verbal podía interrumpirse y entrecortarse por una señal inestable de internet.

Es importante señalar que el uso de los dispositivos electrónicos para desempeñar el trabajo no fue lo único que los docentes tuvieron que gestionar con el entorno familiar que debía atender también obligaciones laborales o escolares en línea: la construcción misma del espacio laboral estuvo en juego. En el centro escolar, el área trabajo estaba dada, acondir cionada para la práctica docente y, aunque la construcción simbólica y objetiva del espacio puede presentar disputas, su habitabilidad aparece como práctica no problematizada, como operatividad institucionalizada que se asienta en regulaciones formales y en la creación de acuerdos informales que la tradición respalda. El traslado del lugar de trabajo al ámbito privado implicó la concertación con el entorno familiar de su uso temporal y material; su adecuación física estuvo en relación con el espectro visual que sería expuesto en cámara; el dominio de las sonoridades que configuran el espacio también tuvo que considerarse. La composición física, relacional, sensorial y ambiental del espacio se volvieron parte de la cotidianidad del docente, incorporándose al mismo tiempo como elementos afectantes del proceso de trabajo. El cuerpo docente debió encontrar las estrategias para resolver por su cuenta las problemáticas que surgieran.

Como se mencionó, el tránsito hacia las clases virtuales no fue automático y tuvo resistencias; la intervención de autoridades para negociar la incorporación de nuevas dinámicas y prácticas fue vital; al respecto, uno de los entrevistados comenta: "tuve que prestar bajo resguardo computadoras de la escuela a algunas maestras porque no querían dar clases [en línea], decían que no tenían el material" (Autoridad, comunicación personal, videollamada, 13 de octubre de 2020). Meses después de que había iniciado el confinamiento en la zona escolar donde se encuentra la primaria a la que se refiere esta investigación, había escuelas que se negaban a impartir clases en línea y no podía obligárseles a lo contrario (Autoridad, comunicación personal, videollamada, 13 de octubre de 2020). La principal opción educativa para estos sectores se limitó a seguir el programa Aprende en Casa.

A continuación, se problematizan los cambios al proceso de trabajo de aquellos docentes que asumieron el reto de trasladar su labor a los foros 
televisivos. La reconstrucción de dicho apartado siguió la práctica etnográfica virtual, la cual permitió analizar como texto los programas educativos; la exposición de los hallazgos se complementa con la información que proporcionó un docente vinculado al proyecto.

\section{a) El trabajo docente en televisión}

La operación de Aprende en Casa, además de tener el reto de adecuar los contenidos educativos a las condiciones del medio, requirió la modificación de las calificaciones laborales y del proceso de trabajo de los docentes que se incorporaron al proyecto. ${ }^{3}$ Una reconfiguración del trabajo nada sencilla, ya que implicó la movilización repentina de un conjunto de disposiciones corpóreas, estéticas y subjetivas que eran ajenas a la actividad docente. En el foro de televisión, la performatividad del trabajo como producción estética -estilo de caminar, hablar, vestir- se vio modificada (Witz et al., 2003): el docente ahora debía dirigir el cuerpo a la cámara, hablar con un muñeco guiñol, adecuar las emociones a las exigencias del director de escena y ceñir su discurso a un guion acorde con la estructura del programa. Bajo estas condiciones, la producción, circulación y consumo de la práctica docente dejaron de estar comprimidas en un solo acto, es decir, el resultado del trabajo aparece como producto acabado después de un proceso de edición en el que no intervienen los profesores. Asimismo, la exposición temática en televisión se complementa con imágenes y videos que buscan captar la atención de quien se encuentra del otro lado de la pantalla; un recurso pedagógico que se asemeja al uso del proyector en el aula; sin embargo, el control de los tiempos, movimientos y contenidos de lo que se presenta resulta ajeno al trabajador. Aunque el docente puede incorporar adecuaciones a su proceso de trabajo, el diseño de lo que se produce no recae en sus manos, cuestión que fragmentó tareas de trabajo que antes se encontraban vinculadas.

Las habilidades docentes ligadas al manejo de grupo resultan centrales en el salón de clases; sin embargo, en el ámbito televisivo, son prescindibles, es decir, se tornan irrelevantes los saberes que logran captar la atención del estudiante que se nota inquieto o tiene la mirada ausente; aunque la televisión posee múltiples recursos para capturar a su audiencia, el mensaje nunca es personalizado ni reconoce al sujeto que requiere una

3 Nuestro informante menciona que la SEP emitió un comunicado en los centros escolares para invitar a los profesores a participar en el proyecto como voluntarios. Atendiendo a esta convocatoria, se incorporó a la producción televisiva, actividad que tiene que complementar con la impartición de clases en línea relacionadas con su centro de trabajo. 
consideración particular. Asimismo, la retroalimentación que genera la interacción cara a cara es una condición irrealizable; la uniformidad de la explicación queda contenida en el discurso prefabricado y vinculado al guion; la respuesta a la duda de quien no entendió la lección debe buscar otro interlocutor. El proceso de trabajo del profesor de TV se fragmenta y, a la manera de Braverman (1974), la tecnología arrebata al docente la capacidad de conocer la totalidad de su actividad. Habría que agregar que el control se ejerce no sólo en la manera en la que se transmite el conocimiento; el dominio también se plasma en el cuerpo en tanto trabajo estético y en la subjetividad en tanto gestión de emociones. Lo importante en la exposición de la performatividad laboral es mostrarse afable todo el tiempo, dirigirse al alumnado con sonrisas que lucen forzadas y luchan por esconder el miedo y los nervios de pararse frente a las cámaras (DocenteTV, comunicación personal, videollamada, 21 de agosto de 2020).

La performatividad amigable del proceso de trabajo se vuelve un imperativo, una forma de control de las emociones que se ejecuta en favor de alguien más (Hochschild, 1982); por lo tanto, es necesario aprender las reglas de comportamiento del nuevo escenario de trabajo (Rafaeli y Sutton, 1987). Cabe precisar que las exigencias prácticas emanadas de la dirección del programa se combinan con formas de autocontrol derivadas de la presión que supone someter al escrutinio público la práctica del oficio. De igual forma, la incorporación de nuevas calificaciones no es el resultado de la adecuación mecánica a los mandatos del productor televisivo, es decir, el saber-hacer y el saber-ser se llevan a cabo también como actos de imitación; la fuente experiencial de la subjetividad del docente busca desenvolverse en correspondencia con la memoria social que configura el espacio en el que se produce la acción.

Esta última consideración dota de agencia al sujeto: aunque existen presiones estructurales para ejercer el trabajo, la práctica no es una simple repetición autómata sino la puesta en juego de facultades reflexivas bajo un entorno espacial configurado por elementos físicos e interactivos distintos a los del centro escolar. Al respecto de la capacidad de agencia, el testimonio de un docente refiere: "los que están allí te dicen dónde te pongas, que estés relax, tienes que aprenderte más o menos los diálogos, y pues hay momentos en los que tú le puedes echar de tu cosecha" (DocenteTV, comunicación personal, videollamada, 21 de agosto de 2020). Lo anterior permite reconocer que, aunque la impartición de clases televisivas busca estanda- 
rizar la comunicación verbal y corporal, existen márgenes de adaptación y adecuación por parte de los sujetos que se incorporan al resultado final del producto televisivo, aunque éste pase por un filtro de edición previo a su transmisión.

Bajo esta relación de tensión entre control y agencia, se reconfigura la dimensión interactiva del trabajo docente. En el ámbito escolar, la interacción se genera con el alumnado y sus padres de familia; es frente a ellos que se negocia el control sobre el proceso de trabajo. No obstante, aunque la práctica docente debe cumplir imperativos de comportamiento y de seguimiento de un programa educativo, la posibilidad de hacer ajustes a la actividad se amplía, al igual que la gestión de sus emociones. En la producción televisiva, en cambio, la interacción y disputa del control se traslada hacia la dirección del programa; el destinatario clásico del trabajo docente -el alumno- queda ausente, se vuelve periférico y deja de incidir directamente en la concreción del servicio. Como puede verse, no sólo las exigencias estéticas y emocionales inciden en la transformación del trabajo docente en televisión, también la formación de nuevas configuraciones relacionales se vuelve condicionante de la práctica.

Para concluir, se puede señalar que el proceso de trabajo docente en televisión se reconfiguró atendiendo las condicionantes físicas, interactivas y de memoria colectiva que producen al espacio. Asimismo, la producción de símbolos y significados tuvo que negociarse y adecuarse a los requerimientos de un sujeto ajeno a la configuración clásica de la práctica, cuestión que implicó para el docente una pérdida del control sobre su proceso de trabajo; la atención a la dirección de escena y la ausencia en la injerencia editorial así lo demostraron. La interacción dejó de ser un componente central de este trabajo y la producción de símbolos sin intervención del usuario imperó.

\section{b) El trabajo docente en línea}

Como se anunció, una de las estrategias adoptadas para complementar al programa Aprende en Casa fue el trabajo docente en línea; una opción educativa que estuvo sujeta a resistencias, disputas y negociaciones entre autoridades y docentes. En el caso estudiado, la propuesta recibió inicialmente una respuesta negativa, pues se argumentaba que no había una regulación formal por parte de la SEP para llevar a cabo la tarea; por lo tanto, desde los primeros meses del confinamiento pandémico y hasta finalizar el ciclo 
escolar 2019-2020, ${ }^{4}$ se acordó el envío sólo de tareas por correo electrónico. Este proceso resultó caótico, ya que el alumnado no tenía conocimientos sobre el uso del correo electrónico, legalmente no podían abrir una cuenta y, por lo tanto, la comunicación dependió de la intervención de familiares (Docente 1, comunicación personal, videollamada, 9 de septiembre de 2020).

Aunque el cuerpo docente accedió a mantener comunicación con los familiares del alumnado vía correo electrónico aun sin estar regulada dicha práctica, las autoridades zonales y la dirección de la escuela siguieron presionando para impartir clases en línea; sin embargo, el rechazo se mantuvo. Como se ha expuesto, los profesores argumentaban que no contaban con las habilidades para el uso de las herramientas tecnológicas, así como que no tenían los dispositivos adecuados ni la conectividad idónea; además, agregaron que las sesiones en línea vulneraban la esfera privada de las partes involucradas en el proceso. La invasión a la privacidad podría generar problemáticas para las que no había un marco de regulación formal: "existía el miedo de si se metía alguien a la sesión que no formara parte de los alumnos y hacía cosas indebidas [...] imagínate la bronca en la que nos metemos" (Docente 1, comunicación personal, videollamada, 9 de septiembre de 2020). Efectivamente, el riesgo era alto; la solicitud de las autoridades para dar clases en línea se sostenía solamente en imperativos morales que demandaban un actuar de sacrificio y nobleza por parte del cuerpo docente (Nota de campo, 28 de agosto de 2020). La ausencia de una normativa obligó a la negociación de la práctica sin garantías de protección para los profesores; al respecto, una autoridad del centro escolar señala:

En la supervisión nos dicen que no los podemos obligar a dar la clase, pero pues sí nos presionan para que hagamos labor de convencimiento [...] no todas las escuelas dan el mismo número de clases, hay directores que me comentan que nada más no logran convencer a sus profes [...] unos nada más dan una clase cada quince días y puras tareas por mail. (Autoridad, comunicación personal, videollamada, 13 de octubre de 2020)

4 Aunque el confinamiento inició a finales de marzo de 2020, la discusión sobre la estrategia a seguir acaeció hasta mediados del mes de abril en nuestro caso de estudio. El año escolar terminó en julio del año en comento. 
En el centro escolar elegido para esta investigación, la negociación del número de clases a impartir se llevó a cabo al menos en tres ocasiones. La primera de ellas tuvo lugar al inicio del confinamiento; en dicha negociación, los docentes se negaron a dar clase y la comunicación con los alumnos se mantuvo vía correo electrónico. Posteriormente, al iniciar el ciclo 2020-2021, se acordaron sesiones en línea de una hora por semana. ${ }^{5}$ Avanzado este periodo escolar, se realizó una tercera negociación para extender el número de horas a tres por semana, las cuales podían ser distribuidas e impartidas de acuerdo con criterios particulares.

Cabe precisar que la disputa por las fronteras del control sobre el proceso de trabajo no se redujo a la aceptación y el rechazo de clases en línea; la ambigüedad de la regulación se tradujo también en la asignación de nuevas tareas, es decir, la dirección del centro escolar - atendiendo las exigencias de la supervisión de la zona escolar- presionó para que los docentes generaran evidencias que demostraran qué se hacía para atender a los alumnos que no asistían a las sesiones virtuales; un reto que debió ser resuelto de diversas maneras, ya sea por medio del envío de correos electrónicos, llamadas telefónicas a los familiares o con la mediación de otros docentes; como refiere un docente, "hay ocasiones en que los niños entran a mi clase pero no a la de inglés, entonces [los profesores] me piden de favor que le comente a la mamá si se pone en contacto con [ellos]" (Docente 2 , comunicación personal, videollamada, 12 de enero de 2021). El seguimiento, vigilancia y justificación de la inasistencia virtual del alumnado se volvió de pronto una nueva responsabilidad del trabajo docente; un ordenamiento que debía ser documentado para su gestión y control burocrático.

La reconfiguración del proceso de trabajo exigía una atención cada vez más personalizada del alumnado; los criterios que demandaba la supervisión de zona para asignar calificaciones dan cuenta de ello: para otorgar una nota baja o reprobatoria, los docentes debían demostrar que habían agotado todas las instancias de búsqueda que tuvieran a su disposición para localizar a alumnos que no asistieron a clases en línea o no entregaron tareas por correo electrónico. Resultaba menester dar múltiples oportunidades para asentar una calificación favorable; aun con todo ello, se corría el riesgo de recibir un llamado de atención si de pronto surgía una queja o inconformidad relacionada con los criterios de evaluación. Para enfrentar

5 Cabe precisar que, a diferencia de los profesores de aula, los de educación física e inglés en ese momento dieron hasta cuatro clases por semana, ya que al estar contratados por horas tienen asignados varios grupos.

Ocampo, R. E. y Cuéllar, A. (2022). La reconfiguración del proceso de trabajo docente bajo el confinamiento provocado por la pandemia. Iberoforum, Revista de Ciencias Sociales, Nueva Época, 2(2), 1-26, Artículos, e000188. https://doi.org/10.48102/if.2022.v2.n2.188 Licencia Pública Internacional - CC BY-NC-ND 4.0 
esta situación, la asignación de calificaciones tuvo que negociarse de forma colectiva, es decir, el cuerpo docente buscó unificar criterios para evitar problemas de reclamo de familiares y sortear así una posible sanción de la supervisión. Ante las ambigüedades que prevalecían en la regulación del trabajo, surgían también resistencias; en este caso, se expresaron como una concertación colectiva para la asignación de calificaciones.

Aunque la negociación para impartir clases en línea y para aceptar nuevas actividades pudo volverse ríspida, la flexibilidad de las condiciones de trabajo logró imponerse. La atención personalizada de alumnos da cuenta de ello. Asimismo, el horario de trabajo quedó diluido al emplearse correos electrónicos como forma de comunicación; un canal mediante el cual se entregarían tareas escolares de aquéllos que, por múltiples rae zones, no podían incorporarse a las clases virtuales. El flujo de esta información no tenía horario; sin embargo, el cuerpo docente estaba obligado a evaluar y atender oportunamente a ese sector de la población escolar. Además, la condición de confinamiento habilitó una práctica particular que radicó en la programación de juntas de un día para otro, lo que asumía que la estadía en el hogar implicaba disposición total sobre el tiempo del trabajador. Podría decirse que, al diluirse los límites que dividen las esferas de la producción y la reproducción, la flexibilidad se impuso como condición práctica del proceso del trabajo docente.

La productividad social que iba configurándose encontraría otras problemáticas en el momento de poner en marcha las clases en línea. Además de demandarse pericia en el uso del software, el cuerpo docente requirió imponer nuevos criterios de orden para controlar las interacciones que se producían en el espacio virtual. Por ejemplo, la disputa por el uso de la palabra tuvo que regularse tal y como sucede en el aula; sin embargo, el llamado al orden requirió adecuar la entonación de la voz y recurrir al empleo de diminutivos para corregir al estudiante que arrebataba la palabra; una sonoridad que se acompasó con gesticulaciones de cordialidad y comprensión. Para los docentes, se mantenía latente el temor a emitir un regaño no avalado por los sujetos habitantes del espacio físico y virtual donde se desarrollaba el trabajo. Esta interacción virtual también exigió ordenar el uso del chat; el control del grupo no sólo implicó la gestión de la sonoridad: la palabra escrita estaba de igual forma en juego; el docente debía estar atento a lo que se decía y planteaba en este terreno. Lo mismo sucedió con el encendido y apagado de las cámaras: la activación de la imagen debió 
negociarse de forma recurrente. El domino de la pantalla como componente físico y virtual también requirió ser normado: fue necesario regular la opción para compartir pantalla a la que tienen acceso docentes y alumnos; aunque éste era un recurso expositivo que facultaba la horizontalidad del diálogo, se conservó la verticalidad en favor del profesor. Como ha quedado expuesto, el encuentro virtual requirió la formación de una productividad social que el docente tuvo que crear improvisando reglas y estrategias pedagógicas para dar funcionalidad y volver operativo su trabajo.

Un factor que debe agregarse es que la reconfiguración del proceso de trabajo también estuvo vinculado a una estructuración de la división social del trabajo mediada por la condición de género: la repartición del horario productivo dependió del cuidado en clave de trabajo (Franco, 2015) que realizan las profesoras en el hogar. En una junta virtual entre docentes, una de ellas expresó: "es que mi problema es que tengo que cuidar a mis hijas también, porque mi esposo también está trabajando en la casa" (Nota de campo, 21 de septiembre de 2020). La noción de cuidado se amplió; ésta no se limitó a la atención que se da a los alumnos en la clase, sino que al mismo tiempo se debía estar pendiente de asistir las necesidades de reproducción de los miembros de la familia. El desarrollo del trabajo docente articuló también el cuidado de sus relaciones de dependencia que, como señala Arango (2011), se asientan sobre una ética que entiende el ámbito familiar como una comunidad basada en el afecto y de preocupación recíproca por el otro, cuestión que desdibuja la condición de subalternidad vinculada al género que subyace y se reproduce en el ámbito privado.

Finalmente, puede decirse que la reconfiguración de la práctica permitió crear la noción de interacción virtual ampliada, la cual ayuda a comprender que el vínculo educativo no se redujo al encuentro docente-alumno; la producción del trabajo en línea fundó un lazo de comunicación indirecta con quienes deambularon el espacio donde se generó la práctica pedagóa gica. La comprensión ampliada de la interacción implica considerar que el proceso de trabajo en línea estuvo sujeto a la evaluación del alumnado y de los entornos relacionales donde se produce la acción. La impartición de clases en línea, a diferencia del trabajo en televisión, no es editable; un error no permite el corte de escena y la repetición que busca estandarizar la acción; en cambio, aunque existen márgenes de improvisación en la televisión, el trabajo siempre puede ponerse en pausa y ser corregido o perfeccionado. El trabajo docente en línea se encontró abierto a la crítica en el mis- 
mo momento de su ejecución; la construcción del vínculo virtual se amplió y la presencia de un otro que transitaba el espacio productivo incidió en la concreción del proceso de trabajo, es decir, en la forma en la que se desplegaron las habilidades pedagógicas, corpóreas y emocionales, así como en la manera en la que se produjeron los signos auditivos, semióticos y estéticos.

Como puede verse, la actividad docente tuvo que reedificarse bajo nuevos condicionamientos estructurales, interactivos y simbólicos; un proceso que exigió la negociación cotidiana del orden en condiciones que obligaron la improvisación constante en la performatividad del trabajo. El oficio del magisterio bajo el confinamiento tuvo que reinventarse para adaptar sus habilidades prácticas a exigencias productivas inéditas.

\section{Conclusiones}

El confinamiento reconfiguró los elementos estructurales, interactivos y subjetivos que intervienen en el proceso del trabajo docente. La transformación súbita provocó que la actividad se desarrollara sobre marcos de regulación ambiguos; para el caso del trabajo en línea, esto implicó una continua improvisación y negociación de las condiciones en que se ejerce la actividad y de la forma en cómo se exponen los contenidos; una condición estructural que contrastó con el trabajo en televisión, en el cual se vio limitada la capacidad del control sobre el proceso de trabajo. Siguiendo la propuesta teórica del "trabajo no clásico", se amplió el concepto de regulación laboral entendiendo que el control se negocia también frente a terceros; para el caso de las clases en línea, esto fue claro al exponer la presión que ejercen los sujetos que deambulan y habitan el espacio de trabajo.

El cambio en las condiciones de trabajo involucró el despliegue de una performatividad laboral distinta a la que se produce en las aulas, es decir, los docentes requirieron adecuar los componentes pedagógicos, estéticos, éticos, de cuidado y emocionales de su actividad a las exigencias tecnológicas, interactivas y espaciales de los dos ámbitos investigados. Una adaptación que se tradujo también en creación y formación de nuevas calificaciones laborales; proceso que, cabe decir, no fue mecánico y dependió de la distribución desigual de saberes, así como de mediaciones en las que se desplegaron resistencias que buscaron limitar el control ejercido por padres de familia y autoridades. Al respecto del acoplamiento del trabajo a lugares inéditos, se puede señalar sobre el caso televisivo la articulación de relaciones laborales con sujetos ajenos al centro escolar, además de reali- 
zar su actividad en correspondencia con la memoria social que configura el espacio en el que se produce la acción. En cuanto al trabajo en línea, el espacio requirió ser producido por el docente mismo, es decir, la disputa por el dominio del lugar, del tiempo y la sonoridad se volvieron parte de su proceso de trabajo; condición que puso en juego la definición y el trazo de las fronteras que dividen lo público y lo privado.

La reconfiguración de la práctica exigió la formación de una productividad social inédita en la que los docentes estuvieron presentes como sujetos activos, aunque condicionados por las particularidades del espacio donde desarrollaron su trabajo. Un proceso que, además de modificar objetivamente la producción del trabajo, redefinió el contenido de la fuente experiencial docente, que puede ser entendida como respuesta subjetiva a la situación concreta inmersa en marcos culturales de referencia que demandaron que el desarrollo del oficio respondiera a exigencias éticas y morales históricamente determinadas, las cuales asignan al oficio un aura de benevolencia y sacrificio alejada de su condición de explotación.

Finalmente, es preciso señalar que la reconfiguración del proceso de trabajo se concretó bajo la estructuración de condiciones flexibles de tran bajo que, al imponerse como condición práctica no regulada formalmente, dejó a la libre interpretación las funciones que la actividad docente debía asumir durante el confinamiento. La ausencia de regulación diluyó las fronteras que dividen las esferas de lo público y lo privado; cuestión que afectó los límites espaciales que se asignaban al tiempo de trabajo: la demanda de atención docente dejó de tener horario. Asimismo, las condiciones flexibles en tanto polivalencia de funciones exigieron la producción del propio espacio de trabajo, la capacitación individual para el desempeño de la actividad y la gestión de recursos para el mismo objeto. El intento de regulación institucional siempre fue un paso atrás al trazar fronteras a una operatividad que ya estaba en marcha; aunque se incorporaron ajustes normativos, no lograron poner límites a la carga de trabajo que asumieron los docentes que accedieron a impartir clases en línea y en televisión.

El anuncio obradorista de una política educativa reivindicativa de los derechos laborales del magisterio - que se pondría en pausa a causa de la pandemia- continuó siendo letra muerta después de un año y medio del inicio del confinamiento. 


\section{Referencias bibliográficas}

Arango, L. (2011). El trabajo de cuidado: ¿servidumbre, profesión o ingeniería emocional? En L. Arango y M. Pascale (comps.), El trabajo y la ética del cuidado (pp. 91-109). La carreta editores.

Braverman, H. (1974). Trabajo y capital monopolista. Nuestro Tiempo.

Burawoy, M. (1979). Manufacturing Consent: Changes in the Labour Process Under Monopoly Capitalism. Macmillan.

Carrillo, J. e Iranzo, C. (2003). Calificación y competencias laborales en América Latina. En E. de la Garza (coord.), Tratado latinoamericano de sociología del trabajo (pp. 179-212). Fondo de Cultura Económica.

Edwards, P. (1990). El conflicto en el trabajo. Ministerio del Trabajo y la Seguridad Social.

Franco, S. (2015). Trabajo de cuidados. Debates y conceptualizaciones. Editorial Universidad de Caldas.

Garza de la, E. (2017). ¿Qué es el trabajo no clásico? Revista Latinoamericana de Estudios del Trabajo, 21(36), 5-44.

Garza de la, E. (2012). La metodología marxista y el configuracionismo latinoamericano. En E. de la Garza y G. Leyva (eds.), Tratado de metodología de las ciencias sociales: perspectivas actuales (pp. 229-255). Fondo de Cultura Económica, Universidad Autónoma de México.

Garza de la, E. (2011a). Trabajo no clásico, organización colectiva y acción colectiva. En E. de la Garza (coord.), Trabajo no clásico, organización y acción colectiva, tomo II (pp. 305-334). Universidad Autónoma Metropolitana, Plaza y Valdés.

Garza de la, E. (2011b). La revitalización del debate del proceso de trabajo. Revista Latinoamericana de Estudios del Trabajo, 16(26), 7-35.

Gilligan, C. (1985). La moral y la teoría. Psicología del desarrollo femenino. Fondo de Cultura Económica.

Hochschild, A. (2003). The Managed Heart, Commercialization of Human Feeling. University of California Press.

Pink, S., Horst, H., Postill, J., Hjorth, L., Lewis, T. y Tacchi, J. (2019). Etnografía digital. Principios y práctica. Morata.

Rafaeli, A. y Sutton, R. (1987). Expression of emotion as part of the work role. The Academy of Management Review, 12(1), 23-37. https://doi. org/10.2307/257991

Witz, A., Warhurst, Ch. y Nickson, D. (2003). The labour of aesthetics and the 
aesthetics of organization. Organization articles, 10(1), 33-54. http:// sgpwe.izt.uam.mx/pages/egt/Cursos/SeminarioTNC/LaobourofAesthetics.pdf

Wolkowitz, C. (2006). Bodies at Work. SAGE Publications. provocado por la pandemia. Iberoforum, Revista de Ciencias Sociales, Nueva Época, 2(2), 1-26, Artículos, e000188. https://doi.org/10.48102/if.2022.v2.n2.188 Licencia Pública Internacional - CC BY-NC-ND 4.0 